\title{
Polymer Electrolytes for Electrochromic Devices
}

M. M. Silva, R. Leones (Centro de Química, Universidade do Minho), R. Alves, R. F. P. Pereira (University of Minho), and V. de Zea Bermudez (University of Trás-os-Montes e Alto Douro)

Polymer electrolytes are currently the focus of much attention as potential electrolytes in electrochemical devices such as batteries, display devices and sensors [1,2]. Generically, solid polymer electrolytes (SPEs) are mixtures of salts with soft polar polymers. SPEs have many advantages including high energy density, no risk of leakage, no issues related to the presence of solvent, wide electrochemical stability windows, simplified processability and light weight. With the goal of developing a new family of environmentally friendly multifunctional biohybrid materials displaying high ionic conductivity we have produced in the present work, flexible films based on different polymers or hybrids incorporating different salts.

The polymer electrolytes studied here have been characterized by means of Differential Scanning Calorimetry, Thermogravimetric Analysis, X-ray diffraction, Polarized Optical Microscopy, complex impedance spectroscopy and cyclic voltammetry. An evaluation of the performance of the sample with the highest conductivity as electrolyte in all solid-state ECDs was performed [3].

Acknowledgments: This work is funded by FCT- Fundação para a Ciência e a Tecnologia, project references Project Pest-C/QUI/UIO686/2013, PEstOE/QUI/UI0616/2014, POPH/FSE for a grant (SFRH/BPD/87759/2012) (R.F.P.P.), POPH/FSE for a grant SRFH/BD/90366/2012 (R.L), grant POPH/FSE for a grant SFRH/BD/97232/2013 (R. A) and COST Action MP1202 "Rational design of hybrid organic-inorganic interfaces.” M. M. Silva acknowledges CNPq, for the mobility grant provided by this institution.

\section{REFERENCES}

[1] F.M. Gray, in Solid Polymer Electrolytes: Fundamentals and Technological Applications, VCH Publishers, Inc. (1991).

[2] J.R. MacCallum, C.A. Vincent, Polymer Electrolyte Reviews, vol. 1, Elsevier, London, 1987.

[3] S. C. Nunes, V. de Zea Bermudez, M. M. Silva, M. J. Smith, D. Ostrovskii, R. A. Sá Ferreira L.D. Carlos and J. Rocha, A. Gonçalves, E. Fortunato "Sol-gel derived potassium-based di-ureasils for smart windows", Journal of Materials Chemistry 17 (2007) 4239-4248. 